\title{
Seven Characteristics of Successful Calculus Programs
}

\section{David Bressoud and Chris Rasmussen}

In these days of tight budgets and pressure to improve retention rates for science and engineering majors, many mathematics departments want to know what works, what are the most productive means of improving the effectiveness of calculus instruction. This was the impetus behind the study of Characteristics of Successful Programs in College Calculus ${ }^{1}$ undertaken by the Mathematical Association of America. The study consisted of a national survey in fall 2010, followed by case study visits to seventeen institutions that were identified as "successful" because of their success in retention and the maintenance of "productive disposition," defined in [NRC 2001] as "habitual inclination to see mathematics as sensible, useful, and worthwhile, coupled with a belief in diligence and one's own efficacy."

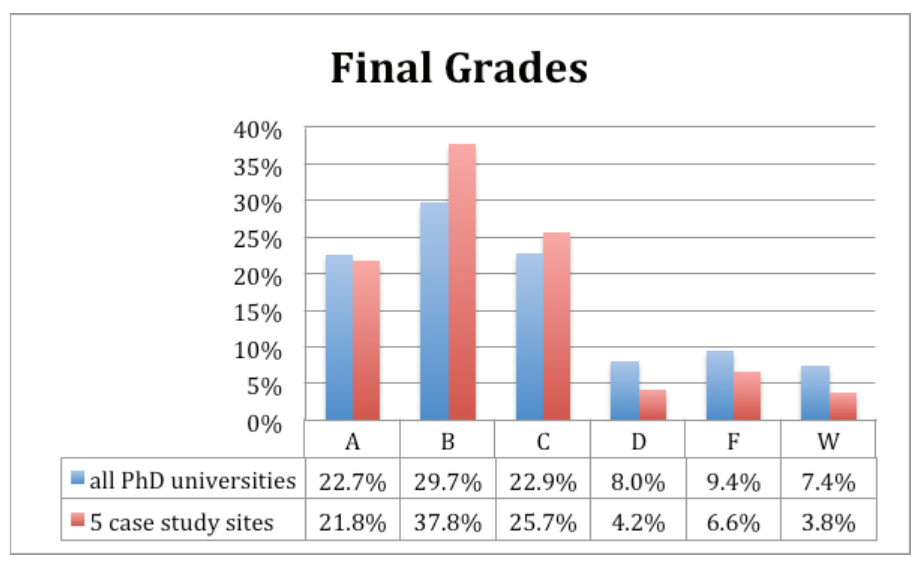

Figure 1. Instructor-reported final grades.

David Bressoud is professor of mathematics at Macalester College. His email address is bressoud@macalester. edu.

Chris Rasmussen is professor of mathematics education at San Diego State University. His email address is crasmussen@mai 1 .sdsu . edu .

${ }^{1}$ NSF \#0910240. The opinions expressed in this article do not necessarily reflect those of the National Science Foundation.

DOI: http://dx.doi.org/10.1090/noti1209
Our survey revealed that Calculus I, as taught in our colleges and universities, is extremely efficient at lowering student confidence, enjoyment of mathematics, and desire to continue in a field that requires further mathematics. The institutions we selected bucked this trend. This report draws on our experiences at all seventeen colleges and universities but focuses on the insights drawn from those universities that offer a PhD in mathematics, the universities that both produce the largest numbers of science and engineering majors and that often struggle with how to balance the maintenance of high-quality research with attention to undergraduate education.

Case studies were conducted in the fall of 2012 at five of these universities: two large public research universities, one large private research university, one public technical university, and one private technical institute. We shall refer to these as:

PrTI: Private Technical Intitute. Private university. Data from nine sections of calculus with an average enrollment of 33 .

PTU: Public Technical University. Public university. Data from seven sections with an average enrollment of 38 and one with an enrollment of 110 .

LPU1: Large Public University. Data from forty-one sections with an average enrollment of 27.

LPU2: Large Public University. Data from four sections with an average enrollment of 200.

LPrU: Large Private University. Data from three sections with an average enrollment of 196 and one section with 32 students.

In addition to productive disposition and improved retention rates, the five also had noticeably higher grades (see Figure 1), cutting the D-F-W rate 
from 25 percent across all doctoral universities to only 15 percent at the case study sites. The difference was in B's and C's. The five case study universities actually gave out a slightly lower percentage of A's than the overall average.

We identified seven characteristics of the calculus programs at these five universities, characteristics that, as applicable, were also found at the other twelve case study sites.

1. Regular use of local data to guide curricular and structural modifications. In his description of the MAA study of Models That Work [Tucker, 1995], Alan Tucker wrote, "No matter how successful their current programs are, faculty members in the visited departments are not yet satisfied with the programs. Experimentation is continuous" [Tucker, 1996]. We found that not only was this true of the successful programs we studied, but these universities used the annual gathering and sharing of data on retention and grade distributions to guide this continuous experimentation. A bad semester was not dismissed as an anomaly but was viewed as an opportunity to understand what went wrong and what could be done to avoid a similar occurrence.

2. Attention to the effectiveness of placement procedures. Though this could be considered part of the first characteristic of successful programs, it received so much attention from all of the universities that we have elevated it to the level of a separate point. These universities evaluate and adjust their placement procedures on an annual basis. We also found a great deal of attention paid to those students near the cutoff, paying particular attention to programs in support of those allowed into Calculus I but most at risk and working with those who did not quite make the cut so that they were placed in programs that addressed their actual needs.

3. Coordination of instruction, including the building of communities of practice. As Tucker reported in 1996, "There is a great diversity of instructional and curricular approaches, varying from one visited department to another, and even varying within a single department." We found this, but we also found that those teaching calculus were in regular communication with the other instructors of this class. Of course, where classes were taught by graduate teaching assistants, there was much tighter coordination of instruction. In all cases, we found that common exams were used. The simple act of creation of such exams fostered communication among those teaching the course. In some cases, communication about teaching was much more intentional, sharing innovative pedagogies, assignments, and approaches to particular aspects of the curriculum. In all cases there was also a course coordinator, a position that was not rotating but a more or less permanent position with commensurate reduction in teaching load.

4. Construction of challenging and engaging courses. This is reflected in an observation that
Tucker made in 1996: "Faculty members communicate explicitly and implicitly that the material studied by their students is important and that they expect their students to be successful in mathematical studies." It also is the first example of effective educational practice in Student Success in College [Kuh et al., 2010, p. 11]: "Challenging intellectual and creative work is central to student learning and collegiate quality." None of the successful programs we studied believed that one could improve retention by making the course easier. Instructors used textbooks and selected problems that required students to delve into concepts and to work on modeling-type problems or even problems involving proofs. Interviews with students, most of whom had taken calculus in high school, revealed that they felt academically challenged in ways that went far beyond their high school courses.

5. Use of student-centered pedagogies and active-learning strategies. This is the second example of effective educational practice in [Kuh et al., 2010], "Students learn more when they are intensely involved in their education and have opportunities to think about and apply what they are learning in different settings." As the first author learned twenty years ago when he surveyed Calculus I students at Penn State [Bressoud, 1994], few students know how to study or what it means to engage the mathematics, and most take a very passive role when attending a lecture. Active-learning strategies force students to engage the mathematical ideas and confront their own misconceptions. At LPU2, where class size makes active-learning difficult, we found it strongly encouraged and supported in the recitation sections.

6 . Effective training of graduate teaching assistants. Graduate students play an important role in calculus instruction at all universities with doctoral programs, whether as teaching assistants in the break-out sections for large lectures or as the instructors of their own classes. The most successful universities have developed extensive programs for training, monitoring, and supporting these instructors. Running a successful training program is not a task that can be handed off to a single person. While there is always one coordinator, their effectiveness requires a core of faculty who are willing to participate in the graduate students' training that takes place before the start of the fall term and to assist in visiting classes and providing feedback.

7. Proactive student support services, including the fostering of student academic and social integration. This is a broad category that ranges from the building of a student-faculty community within the mathematics department to the specifics of support mechanisms for at-risk students. These are addressed in three of the effective practices identified in [Kuh et al., 2010]: "Student Interactions with Faculty Members," "Enriching Educational Experiences," and "Supportive 
Campus Environment.” The first is mentioned in [Tucker, 1996]: "Extensive student-faculty interaction characterizes both the teaching and learning of mathematics, both inside and outside of the classroom." The universities we visited had rich programs of extracurricular activities within the mathematics department. They also had a variety of responses to supporting at-risk students. These included stretching Calculus I over two terms to

Table 1. Instructor Responses to 2010 Survey Questions on Practices in Calculus I.

\begin{tabular}{|l|c|c|c|c|c|c|}
\hline Instructors & \multicolumn{4}{|c|}{$\%$ who do this often or very often } \\
\hline & $\begin{array}{c}\text { Other doc- } \\
\text { toral } \\
\text { universities }\end{array}$ & PrTI & PTU & LPU1 & LPU2 & LPrU \\
\hline Lecture & $84 \%$ & $83 \%$ & $71 \%$ & $63 \%$ & $100 \%$ & $100 \%$ \\
\hline Use online homework & $61 \%$ & $50 \%$ & $100 \%$ & $91 \%$ & $0 \%$ & $100 \%$ \\
\hline $\begin{array}{l}\text { Allow graphing calculators } \\
\text { on exams }\end{array}$ & $45 \%$ & $0 \%$ & $57 \%$ & $97 \%$ & $0 \%$ & $0 \%$ \\
\hline $\begin{array}{l}\text { Ask students to explain their } \\
\text { thinking in class }\end{array}$ & $36 \%$ & $33 \%$ & $57 \%$ & $82 \%$ & $75 \%$ & $33 \%$ \\
\hline $\begin{array}{l}\text { Have students work together } \\
\text { in class }\end{array}$ & $18 \%$ & $17 \%$ & $57 \%$ & $97 \%$ & $0 \%$ & $33 \%$ \\
\hline Hold whole class discussions & $16 \%$ & $17 \%$ & $43 \%$ & $55 \%$ & $0 \%$ & $33 \%$ \\
\hline $\begin{array}{l}\text { Have students give presenta- } \\
\text { tions in class }\end{array}$ & $1 \%$ & $17 \%$ & $0 \%$ & $36 \%$ & $0 \%$ & $0 \%$ \\
\hline
\end{tabular}

Key for Table 1: PrTI = Private Technical Institute, $\mathbf{P T U}=$ Public Technical University, LPU 1 = Large Public University, LPU2 = Large Public University, LPrU = Large Private University

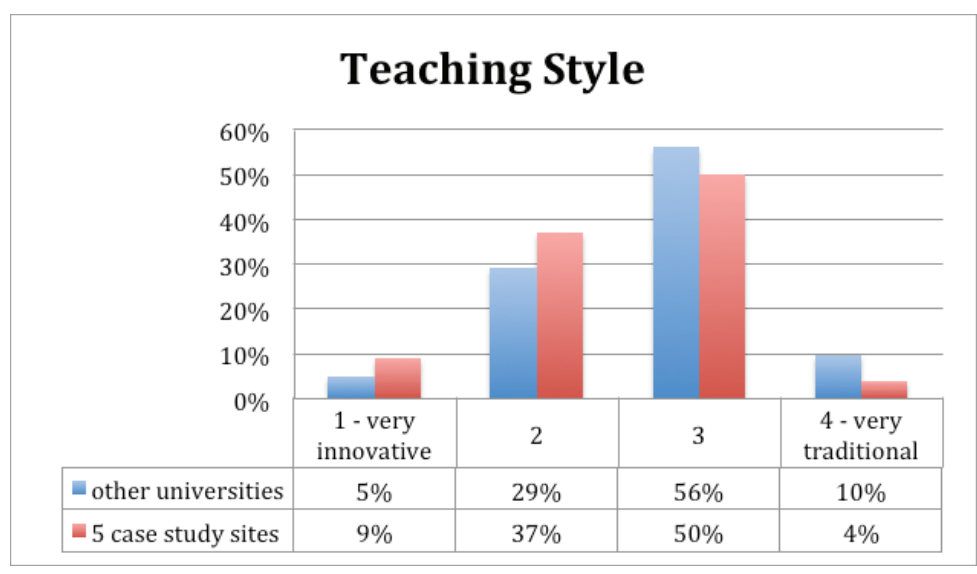

Figure 2: Instructor self-assessment of teaching style.

\section{Students Learn Best from Lecture}

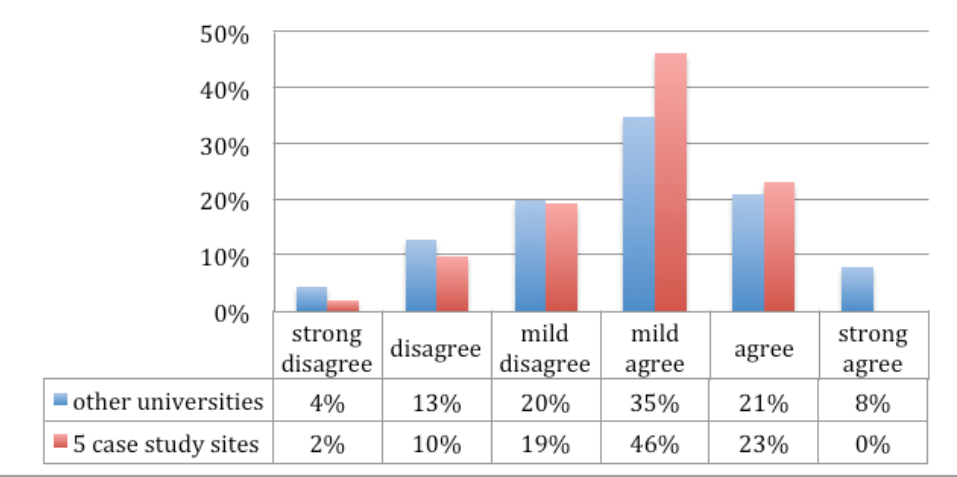

Figure 3: Instructor agreement with statement, "Calculus students learn best from lectures, provided they are clear and well organized." allow for supplemental instruction in precalculus topics, providing "fall-back" courses for students who discovered after the first exam that they were in trouble in calculus, and working with student support services to ensure that students who were struggling got the help they needed. There also were heavily utilized learning centers that attracted all students as places to gather, work on assignments, and get help as needed. Often these were centers dedicated solely to helping students in calculus. What was common among all of the successful calculus programs was attention to the support of all students and a willingness to monitor and adjust the programs designed to help them.

There were some dramatic differences between instruction at the doctoral universities that were selected for the case study visits and instruction at all doctoral universities (see Table 1). Where the section size facilitated this-at PrTI, PTU, LPU1, and one section of LPrU-instructors made much less use of lecture and much more use of students working together, holding discussions, and making presentations. Three of the five have almost universal use of online homework, and a fourth uses it for half of the sections. Graphing calculators were allowed on exams in two of the five universities, though use was not consistent across sections. The most striking difference between these five universities and the overall survey was the number of instructors who ask students to explain their thinking.

Instructors at the case study sites still consider themselves to be fairly traditional (see Figure 2), though slightly less so than the national average. They also tend to agree with the statement, "Calculus students learn best from lectures, provided they are clear and well organized" (see Figure 3). Interestingly, not a single instructor at any of the case study sites strongly agreed with this statement. On the other hand, the instructors at the case study sites were slightly less likely to disagree with it. They clumped heavily toward mild agreement, suggesting an attitude of keeping an open mind and a willingness to try an approach that might be more productive.

\section{References}

[Bressoud, 1994] D. BRESSOUD, Student attitudes in first semester calculus, MAA Focus, vol. 14, (1994), 6-7.

[Kuh et al., 2010] G. D. KUH, J. KINZIE, J. H. SCHUH, and E. J. WhitT, Student Success in College: Creating Conditions That Matter, Jossey-Bass, 2010.

[NRC 2001] National Research Council, Adding It Up: Helping Children Learn Mathematics, Kilpatrick, Swafford, and Findell (eds.), National Academy Press, 2001.

[Tucker, 1995] A. Tucker, Models That Work: Case Studies in Effective Undergraduate Mathematics Programs, MAA Notes \#38, Mathematical Association of America, 1995.

[Tucker, 1996] _____, Models that work: Case studies in effective undergraduate mathematics programs, Notices of the AMS, vol. 43, (1996), 1356-1358. 